\title{
A Survey on Advancement of Baby Cradle
}

\author{
Madhuri P. Joshi ${ }^{1}$, Deepak C. Mehetre ${ }^{2}$ \\ ${ }^{1}$ Department of Computer Engineering, KJCOEMR, SPPU, Pune, Maharashtra, India \\ ${ }^{2}$ H.O.D, Department of Computer Engineering, KJCOEMR, SPPU, Pune, Maharashtra, India
}

\begin{abstract}
Baby care is an important factor in human life from centuries. An adequate sleep is necessary for good health. Hence the special bed for baby i.e. cradle is in use from centuries. According to comfort and need, the design of cradle is changed. Technology played vital role in this change. This paper briefly describes the advancement in the cradle over period.
\end{abstract}

Keywords: Alert System, Cradle, Cradle-Automation, Sensors

\section{Introduction}

An infant bed is a bed specially designed for very young children or newborn. It is called as "cradle" in British English or "crib" in American English and bassinet (derived from French word bassin). Generally, the Bassinet is used for newborn to four month old babies. Sufficient, uninterrupted sleep is needed to build a good health. The more quality sleep a baby gets, the more he or she grows. Hence from centuries, different types of beds are made especially for babies. By the time according to requirement, advancement is done in the design of this bed or cradle.

\section{Types of Cradles}

\section{Traditional cradle}

The traditional cradle is an infant bed which is generally non-mobile. Many of these have swinging facility. The following figure shows the traditional cradle design.

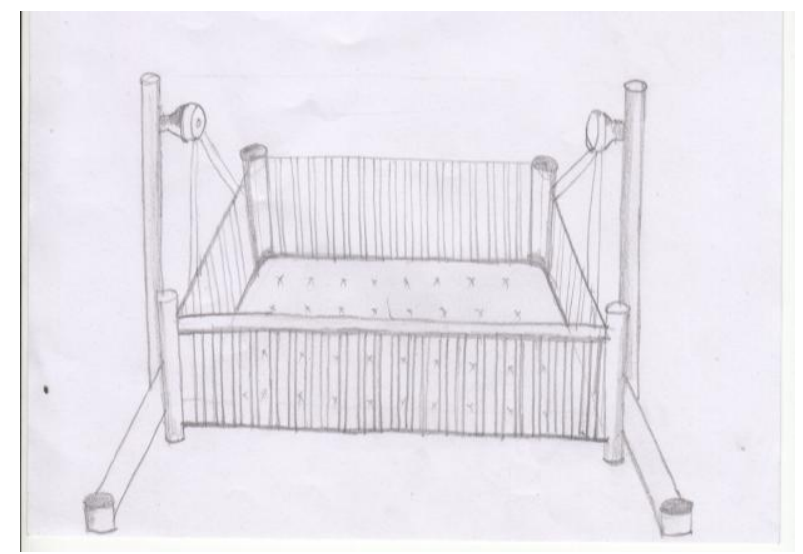

Figure 1: Traditional Wooden Cradle
Advantages
1) The traditional cradles are sturdy.
2) They are good for baby's safety.

\section{Disadvantages \\ 1)They need to swing manually which can be time consuming and difficult for mother while carrying other home duties. \\ 2) They are difficult to carry.}

\section{Bassinet}

The bassinet is generally a basket like container which does not have swinging facility like cradle. Nowadays, the traditional bassinet's design is changed with the addition of wheels so that it can be moved from one place to another easily.

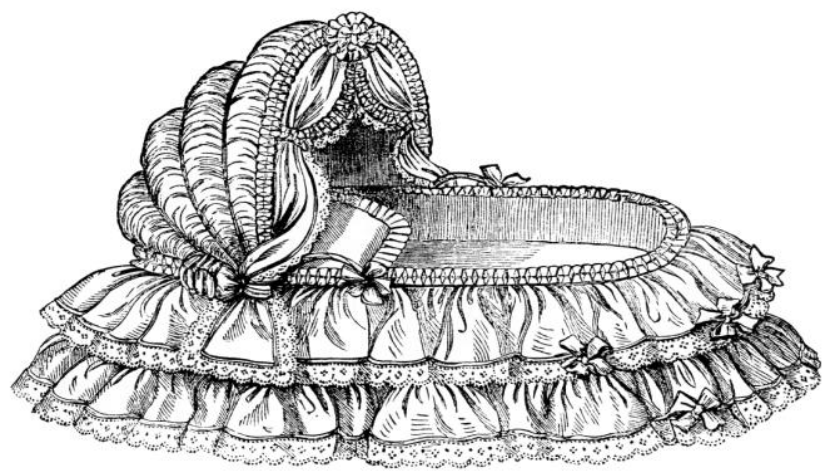

Figure 2: Bassinet sketch

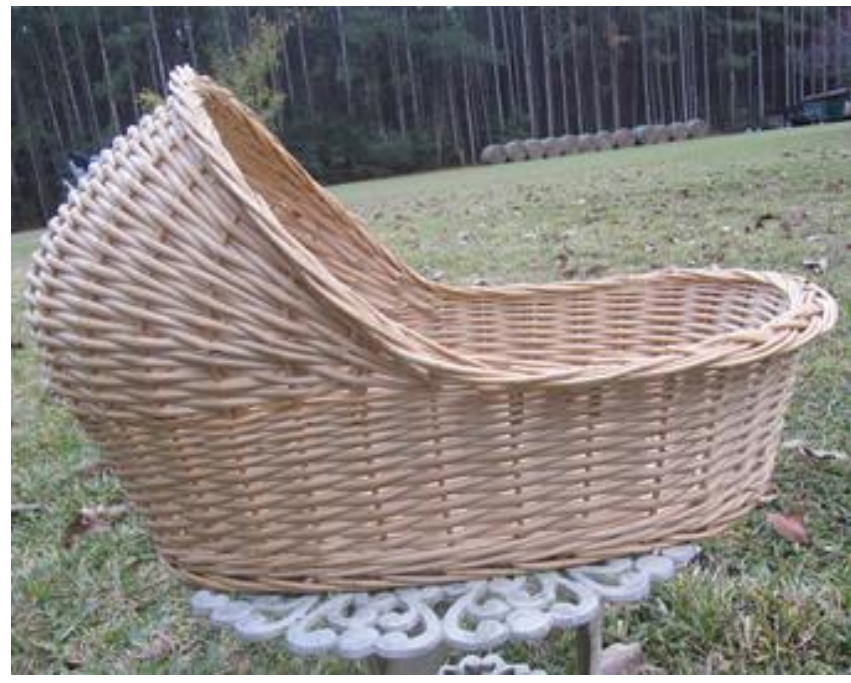

Figure 3: Vintage Bassinet

\section{Advantages:}

1) They are easy to carry.

2) They are good for newborns.

\section{Disadvantages:}

1) They are not comfortable for toddlers.

2) They don't have swinging facility.

\section{Volume 6 Issue 7, July 2017}




\section{International Journal of Science and Research (IJSR) \\ ISSN (Online): 2319-7064}

Index Copernicus Value (2015): 78.96 Impact Factor (2015): 6.391

\section{Baby Hammock}

A hammock is a sling made of fabric and is suspended between two points for swinging. In India, hammocks are in use from centuries for infants and are more comfortable than the cradle. The baby hammock is called as "Hindola" in Sanskrit mythology and is commonly known as "Jhoola" in general.

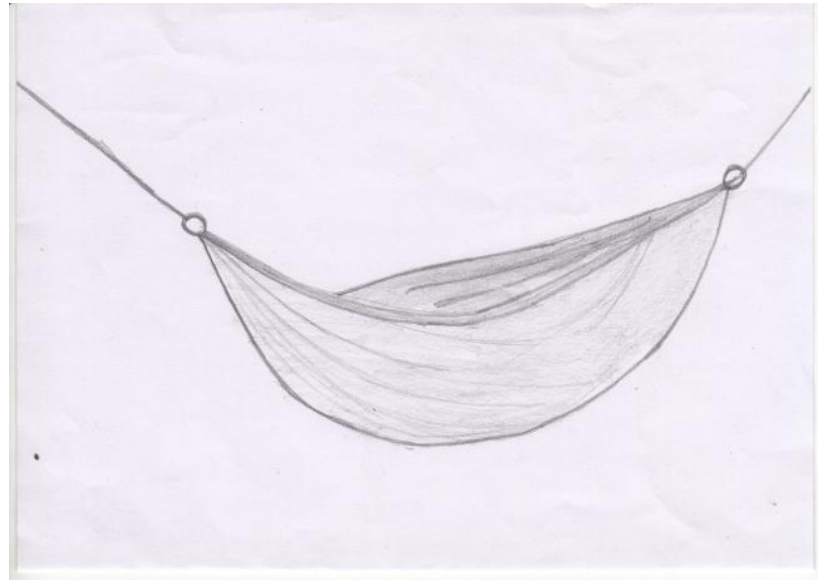

Figure 4: Baby Hammock

\section{Advantages:}

1) They are not so expensive.

2) Cloth hammock can hold baby snugly.

\section{Disadvantages:}

1) They have some safety related issues.

2) Suffocation Risk

3) Baby can get injure by falling out of hammock.

\section{Foldable and Portable Cradle}

It is a light weight cradle. It is easy to carry. It can be bassinet or hammock or crib with folding facility.

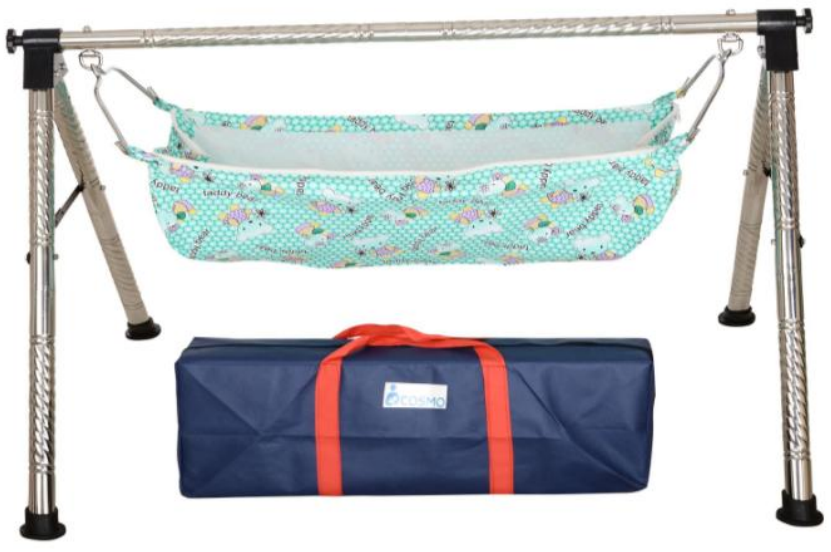

Figure 5: Foldable Cradle

\section{Advantages:}

1) They are easy to carry.

2)Drawbacks of bassinet and hammock are overcome with the design of such cradle.

\section{Disadvantages:}

1) Cradle with auto swing facility are still expensive.

\section{Forward Rocking Cradle}

This is new advancement in design of traditional cradle or bassinet. The normal side to side swinging motion is changed to back and forth.

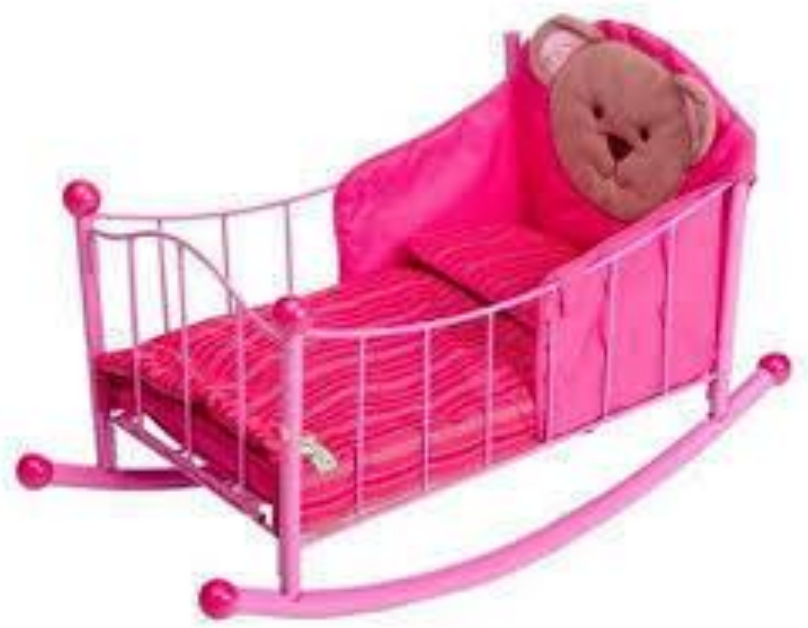

Figure 6: Forward Rocking Cradle

\section{Overview of Advancement in Cradle with new Technologies}

The traditional baby cradle which was in use from centuries was made up of wood. This cradle hangs from the top of the wooden pole to give swinging facility. A mattress is placed in the cradle to give baby warmth and comfort. The swinging action can only be performed manually in such cradles.

The cradle design goes on changing according to need and comfort. The swinging action of cradle is first made automatic with the help of electric motor.

Later, an automatic swinging cradle with safety features was invented by Marie R. Harper. The side to side rocking action facility is given to the cradle with the help of oscillatory action motor. The rocking can be stopped with slight external force. [1]

An electronic device was invented to give automatic swinging facility to traditional cradle. Sensitivity control was used to actuate the crib's swinging based on baby cry sound level. The timer was used to swing up to specific time. [2] Later research was carried out on baby cry analyzer in which sound is amplified with amplifier circuit. Pulse signal having zero crossings which are aligned with zero crossings of this amplified signal is generated by pulse generator circuit. Then baby cry is detected by signal recognition circuit. [3]

Automatic baby rocker was then invented which consists of noise sensor for baby cry detection. Hence the crib would rock automatically if baby cry sound is detected. The Arduino Atmega328 microcontroller which would receive the signal from noise sensor was used to control DC motor to rock the crib. Colorful LED lights were used for baby's entertainment. Also cradle had 6 speeds for rocking motion. 


\section{International Journal of Science and Research (IJSR) \\ ISSN (Online): 2319-7064}

Index Copernicus Value (2015): 78.96 | Impact Factor (2015): 6.391

[4] An algorithm for self sway-adjusting bassinet was then proposed. Here bassinet is made up of sensor network which will adjust swaying. It also gives different signals to control circuits if baby is crying inside bassinet. On detection of baby cry sound, bassinet starts swinging. Its rhythm can be adjusted automatically with use of three pressure sensors which are located at the bottom of bassinet. Two sensors are at left and right of the bottom and one at the centre.[5]

Misha Goyal and Dilip Kumar proposed E-baby cradle which automatically swings on detection of baby cry and can generate alarm on bed wet condition. [6]

To make this cradle system more advanced, Anritha Ebenezer proposed use of GSM technology in which cause of alarm can be sent as message to the parent. [7]

\subsection{System Overview}

The latest automatic cradle system is described here.

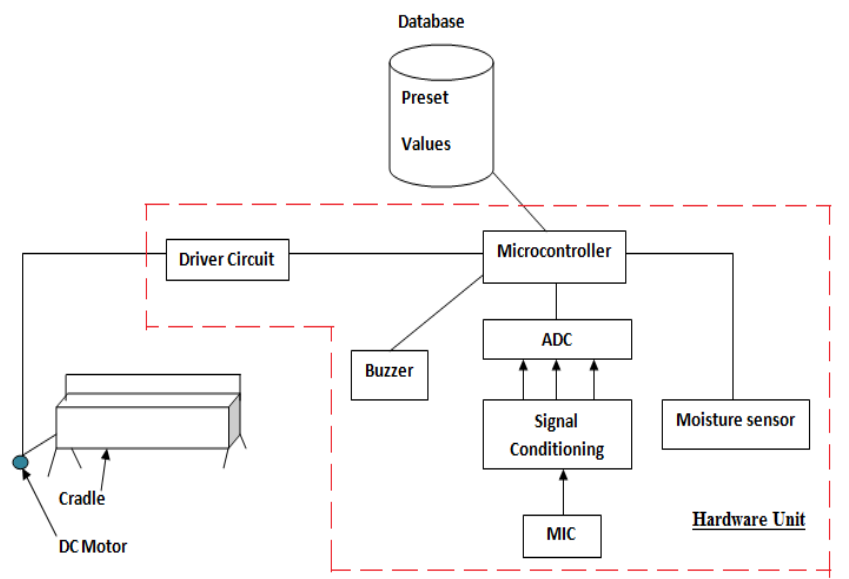

Figure 7: General architecture of an advanced cradle

Figure 7 shows working of advanced cradle. It consists of hardware unit which will control automatic swinging of cradle on detection of baby cry voice.

Baby cry voice is an input in $\mathrm{dB}$ which is compared with preset value and if it is greater than preset value then cradle starts swinging. Here preset value is decided by taking lowest sound level from samples of baby cry voice. This value is then stored in database for further comparison.

Sound level $(\mathrm{x})=20 \log \left(\mathrm{v}_{\text {in }} / \mathrm{v}_{0}\right) \mathrm{dB}$

Where,

vin $=$ Voltage $(A D C$ count $)$ when baby is crying

$\mathrm{v} 0=$ Average reference voltage (ADC count) when baby is not crying. [6]

\subsection{Algorithms}
Algorithm for Automatic Swinging based on baby cry:
1) Start
2) Select lowest value as preset value (y) from sample sound values.
3) Take Sound value as input (x)
4) Check if $x>y$, if true swing cradle for two minutes else

goto 3

5) Stop.
Algorithm for alarm on detection of wet mattress:
1) Start
2) Check if mattress wet, if true goto 3 else repeat 2.
3) Generate alarm.

\subsection{Block diagram}

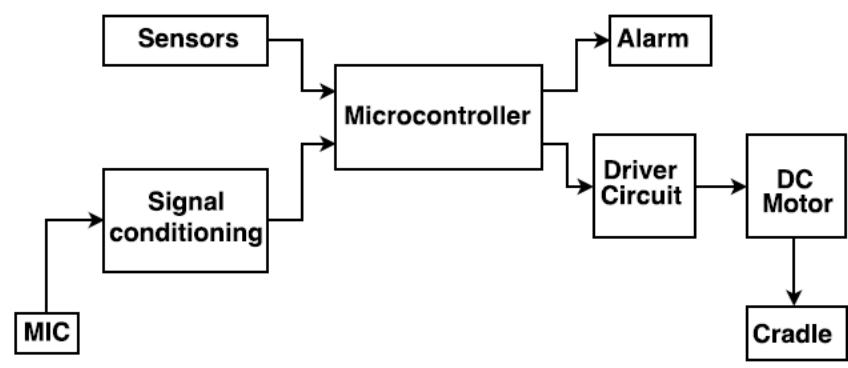

Figure 8: Block diagram of Automatic Cradle

As shown in figure 8. Advanced cradle has following building blocks.

1)Sensors: This unit consists of different sensors like moisture sensor, temperature sensor etc.

a) Moisture sensor is used to detect if the mattress in the cradle is wet or not. Accordingly alarm will be generated.

b) Temperature sensor can be used to check suitable environment for baby.

2)MIC: It is the microphone which will detect the baby cry sound and convert it into electrical signal. The amplifier will receive this electrical signal as input.

3)Signal Conditioning: The electrical signal provided by MIC is amplified with an Op-amp amplifier. Then it is used by microcontroller.

4)Microcontroller: It is used to convert the received amplified signal to digital signal. PIC or Arduino microcontroller is used to control the driver circuit which starts the motor to sway cradle after satisfying condition.[4][6]

5)Driver Circuit: Motor needs specific power like $12 \mathrm{~V}$ or $5 \mathrm{~V}$ etc. Such necessary power is supplied by driver circuit. It prevents other IC and electronic components from electrical damage.

6) Motor: It is used to sway cradle. AC or DC Motor can be used. [4][6]

7)Alarm: It is an alert generated by the buzzer which will be activated in following conditions:

a) If mattress in the cradle is wet

b)If baby does not stop crying after specific time, indicating baby needs personal attention.

\section{Conclusion}

Baby care is an important duty as they are our future. Technology played an important role in cradle's automation. It is observed that baby can get better attention with advanced cradle. Both parents and baby can get good sleep. Although automated cradle cannot handle crying baby every time as the reason might be huger etc, it can lower the work 
of mother. Hence with development of technology guardianship can be easier.

\section{References}

[1] Marie R. Harper, La Mirada, Maxine R. Blea:, "Automatically rocking baby crdle", US3769641, Date of Patent: Nov. 6, 1973.

[2] Gim Wong:, "Automatic bay crib rocker", US3952343, Date of Patent: Apr. 27, 1976.

[3] Chau-Kai-Hsieh, Chiung Lin, Taiwan:, "Baby cry recognizer", US5668780, Date of Patent Sep. 1997.

[4] Steven Bang; Richard Lam; Natalia LoCicero;"Rock Me Baby: The automatic baby rocker" Project for, San Jose State University, Department of Mechanical and Aerospace Engineering, May 17, 2011.

[5] Yang Hu, Weihua Gui; "Adaptive sway control for baby bassinet based on Artificial Metabolic Algorithm", School of Information Science and Engineering, Central South University, China.

[6] Misha Goyal and Dilip Kumar; "Automatic E-Baby Cradle swing based on Baby Cry ", IJCA vol 71 No 21, June2013.

[7] Anritha Ebenezer, Anupreethi S; "Automatic cradle movement for infant care", Undergraduate Academic Research Journal (UARJ), ISSN: 2278-1129, vol-1, Issue-1, 2012.

[8] https://babykidscarezone.wordpress.com/tag/cradletypes/

[9] https://www.babycenter.in/x1021727/is-it-safe-to-use-ababy-hammock-ijhoolai 